\title{
RESENHAS
}

\section{Mujeres maestras. Identidades docentes en iberoamérica}

\author{
por Ana María Barbero Franco
}

A través de los diversos capítulos que conforman este libro (veintiuno), Ricar Huerta nos introduce en el particular mundo de las mujeres maestras. De una forma sensible y atenta a la identidad y feminidad de este grupo, se entrelazan las historias y vivencias de mujeres que ejercen su profesión desde la convicción de que ser maestra es una declaración de principios y un compromiso como mujer, ejercido desde el conocimiento, la experiencia, el respeto al otro, la paciencia, la motivación, la constancia y la implicación personal. Se trata en definitiva de una "miradad critica hacia todo lo que se construye culturalmente en torno a la visibilidad" tomando como referencia este colectivo.

Encontramos en este "paseo literario y visual" tres voces diferentes: la del del autor y artista, que interpreta estas vi-

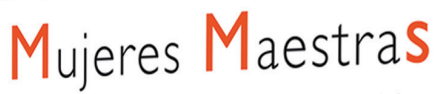

Identidades docentes en Iberoamérica

Ricard Huerta

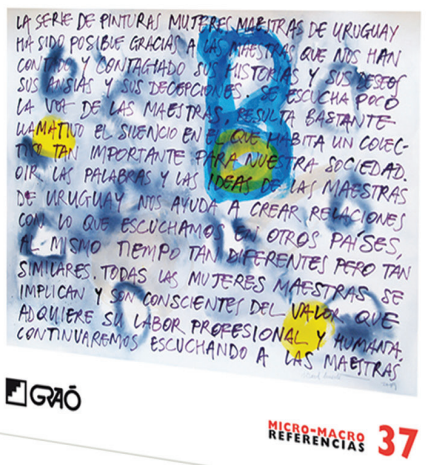

vencias y las traduce en su propia experiencia artística como obras de arte donde las palabras y las grafías se incorporan a todo un mundo de formas y colores; la de los alumnos que a través del dibujo representan su visión particular de la maestra, su maestra, recurriendo para ello a un ejercicio de dibujo retratístico en el cual la mirada del otro se transforma en un trabajo preciso de obsevación de la modelo; y la mirada introspectiva y reflexiva de la maestra en relación a sí misma, a sus deseos y ansiedades, a sus motivaciones, en definitiva, a su geografía personal.

Siguiendo las pautas de Ma Jesús Angra, quien "nos anima a indagar en las narrativas personales más allá de los conceptos o esquemas tradicionales(AGRA cit. por HUERTA,2012:90) y tomando precisamente como referencia esas narrativas personales de maestras en Chile, Colombia, Cuba y Uruguay, el estudio incide en la necesidad de dar voz a estas mujeres que desde el ejercicio diario de su profesión son la clave para la creación de las identidades, individuales o colectivas.

Estas visiones dan lugar a otras actividades como son las conversaciones en el aula y fuera de ella sobre el papel trascendental que estas mujeres ejercen en la vida de la escuela, de la familia y de la comunidad como transmisoras de valores y saberes. Otro aspecto importante es la organización de exposiciones en los museos, donde todos los artefactos artísticos producidos tienen su lugar, con los objetivos de valorar el trabajo de las maestras valorizando así su presencia y acercar a los niños y niñas al arte.
Título: Mujeres Maestras. Identidades Docentes en Iberoamérica

Autor: Ricard Huerta (2012)

Editora: Editorial Graó 
En este libro, las maestras entrevistadas reconocen la necesidad de integrar las artes en las escuelas, dado que las artes son una herramienta poderosa para la formación de los alumnos, para el desarrollo de un espíritu crítico, y para el fomento de la creatividad. De esta forma, conociendo de antemano el entramado de relaciones que permiten el arte y sus viviencias, y siendo consciente de las dificultades sentidas por las maestras en relación a este territorio complejo de las artes, Ricard sostiene un modelo de educación artística desde la cultura visual. EI autor propone una formación que incluya no sólo aspectos relacionados con la producción artística en general, sino también orientada al estudio de la cultura visual (considerando en este punto las aportaciones de Paul Duncun en relación a todo lo referido a los elementos estéticos con los que estamos familiarizados).

Por otro lado, descubrimos entre líneas una preocupación constante sobre la necesidad de actualizar los conocimientos a través de una formación a lo largo de la vida y sobre la necesidad de dotar a las maestras de las competencias básicas para saber lidiar con los cambios y acontecimientos que en el día a día se suceden, atendiendo para ello a la diversidad de visualidades, contextos y metaculturas.

Ricard Huerta, en este libro, nos guía hacia una nueva forma de acercanos e interpretar la "otroridad", la existencia de personajes que pasan a veces invisibles, pero con un rol importante en nuestra sociedad. Mujeres, con nombre y apellido, que forman parte de nuestra cotidiano y que ejercen una gran influencia en nuestras vidas. Comparte además su gratitud hacia este grupo, trayendo ante nosotros la posibilidad de conocer un proyecto bien estructurado de intervención artística, con cinco años de andadura, que desde las premisas de la educación en artes visuales, se centra en las vivencias de estas mujeres, hijas, hermanas, amigas, maestras...

Lo que hace de esta investigación un proyecto cercano es la forma directa como son presentadas estas historias: en primera persona y dejando que el discurso fluya de tal forma que el lector se incorpora a la conversación como un elemento más de este acto comunicativo.

Ser maestra y ser mujer presupone, en muchos casos, una estrecha relación con el ser madre, con el ser compañera, con el ser amiga. Un autentico "relato de particularidades".

Ana María Barbero Franco Artista Visual e Investigadora.

\section{Referência bibliográfica:}

Huerta, R. (2012): Mujeres Maestras. Identidades Docentes en Iberoamérica. Colección Micro-Macro REFERENCIAS. Barcelona: Editorial Graó. 